\title{
16
}

\section{New approaches for integrating palaeomagnetic and mineral magnetic methods to answer archaeological and geological questions on Stone Age sites}

Andy I. R. Herries

\author{
Human Origins Group and Primate Origins Program \\ School of Medical Sciences \\ University of New South Wales \\ Sydney, Australia. \\ a.herries@unsw.edu.au \\ Geomagnetism Laboratory \\ Oliver Lodge, University of Liverpool, UK \\ andyherries@yahoo.co.uk
}

\section{Introduction and aims}

Archaeomagnetism as defined here is the use of magnetic methods of analysis on archaeological materials and deposits, although in its widest context it refers to the magnetisation of any materials relating to archaeological times. It is most widely known for its use in dating, but more recently it has been utilised for other purposes including site survey, sourcing and palaeoclimatic reconstruction. These applications have different site requirements, as discussed below. Two main methods of analysis exist: those that look at the direction and intensity of fossil remnant magnetisations, as in palaeomagnetism; and those related to looking at the mineralogy, grain size and concentration of minerals within a rock or sediment, as in mineral (rock, environmental) magnetism. In the later case, identification of these parameters is achieved by different types and strengths of laboratory-induced remnant magnetisations and/or heat into samples to see how they react or alter.

Magnetic methods have, over the last 10 years, been increasingly used as a Quaternary method of analysis for a variety of applications including dating, sediment-source tracing, and palaeoenvironmental/climatic reconstruction. While these methods have been used on some archaeological sites (e.g. Ellwood et al., 1997; Dalan and Banerjee 1998; Moringa et al. 1999; Gose 2000; Peters et al. 2001), their application has been sporadic and their potential as a major tool for reconstructing archaeological data remains underutilised. This paper provides a review of methods of archaeomagnetic analysis to show the potential for recovering various types of primary data that can be integrated to form a powerful tool for reconstructing archaeological site evolution and behavioural patterns. The paper also provides preliminary data from a number of Stone Age cave sites in South Africa and Spain. 


\section{Mineral magnetism}

\section{Sediment sourcing, input, alteration and palaeoclimatic modelling}

Mineral magnetic studies examine the magnetic nature (minerals, grain sizes and concentration) of the sedimentary input into a depositional system and the various processes that have acted on that material both before and after its deposition in that system. Soil formed on volcanic soils will have a very different magnetic character to soils formed on karstic landscapes. A study of the magnetic mineralogy of cave sediments can therefore show changes in sedimentary input, such as a change from locally derived material to material derived from further afield. This particularly occurs for sites where sediments are deposited by aeolian activity due to changes in wind speed and direction, which can change between glacial and interglacial periods (Begét 2001). In fluvially derived deposits, changes generally tend to reflect more locally changing conditions, such as changes in pedogenic activity, soil cover, weathering and erosion. A study of the magnetic mineralogy of sediment sequences can often be used as a palaeoclimatic proxy record because these processes are governed by climatic factors such as rainfall and temperature variations. These are in turn driven by glacial/interglacial cycles. Such palaeoclimatic proxy records have primarily been undertaken on lake and marine sequences (for example, Peck et al. 2004; Williamson et al. 1998), but work has shown that cave sediments are also suitable, as they are relatively protected from external climatic processes after deposition (Herries 2006).

Mineral magnetic analysis of sediment sequences can reveal a climatically-driven signal for a number of reasons. Primary and secondary iron phases in rocks and sediments are transformed by weathering and various other climatically driven processes into secondary iron oxides (such as magnetite, maghaemite and haematite), hydroxides (such as goethite) and sulphides (such as pyrrhotite). Most often, these pedogenic processes convert primary and secondary iron into magnetite, with later oxidisation to maghaemite through oxidisation/reduction cycles (Maher 1998). This is known as pedogenic enhancement and it produces a dominance of these ferrimagnetic minerals. With prolonged weathering, these processes may also cause the formation of anti-ferromagnetic minerals, haematite and goethite. The degree of pedogenic enhancement is not only determined by climatic and environmental processes but also by the local lithology, which provides the initial magnetic input into the pedogenic system through weathering of underlying rock strata. In certain rocks, iron oxides, hydroxides and sulphides may already coexist with amorphous iron. In igneous landscapes magnetite is the dominant iron oxide, whereas sedimentary rocks may contain significant haematite, especially in sandstones. As large amounts of highly magnetic phases are weathered directly from the local rock strata in volcanic landscapes, the soils tend to show little pedogenic enhancement. The greatest enhancement is seen in rock types that do not contain large amounts of primary iron oxides, such as limestone (Maher 1998).

Pedogenic formation of ferrimagnets is driven by temperature and moisture. It appears to be favoured in well-drained, poorly-acidic soils on weatherable, Fe-bearing (but often not Fe-rich) substrates in a climate that produces wetting/drying cycles (Maher 1998). Excessively arid, waterlogged or acidic soils display little pedogenic enhancement. Maher and Thompson (1995) suggest that in many cases maximum values of strong ferrimagnetic mineral phases, and so greatest pedogenic enhancement, correlate well with absolute rainfall. However, in cases where a certain rainfall threshold is exceeded, water-logging occurs and can result in the depletion of magnetic minerals by processes such as gleying (Liu et al. 1999). Detailed in situ magnetic susceptibility (MS) measurements of multiple sections can quickly identify the potential of a site for palaeoclimatic analysis by identifying bulk changes in ironbearing minerals. However, to understand fully the magnetic mineralogical changes, a suite of mineral magnetic measurements needs to be taken. Other analytical techniques for characterising mineralogy (e.g. XRF, XRD, FTIR) can most often not be used due to the small amounts of magnetic material within the samples. 
The survey and identification of archaeological sites using archaeomagnetism is based on locating strong magnetic anomalies that are normally related to the use of fire by humans (Mullins 1977). These anomalies can be strongly magnetised rocks that once made up a fireplace or sediments that have been anthropogenically altered. Palaeoclimatic analysis on archaeological sites is complicated by anthropogenic alteration of the deposits after deposition. It is therefore of primary importance to understand how the heating of sediments affects the magnetic mineralogy of the deposits. Magnetic measurements are sensitive to fire histories because burning causes the transformation of trace iron within the fuel source itself or/and within sediments associated with the heating (Peters et al. 2001, 2002). Changes between different minerals and different grain sizes can occur; these are dependent on the temperature, longevity and atmosphere of heating (Herries and Kovacheva 2007). Oxidising conditions cause the formation of fine- to ultra-fine-grained single domain ferrimagnetic minerals and at higher temperatures, haematite (Herries et al. 2007a). In contrast, reducing conditions cause the formation of larger stable single-domain grained magnetite (Herries et al. 2007a). While heating of sediments in kilns and ovens might produce a purely reducing environment (Herries et al. 2007a), campfires, as seen on Stone Age sites, almost always produce an oxidising or mixed environment of heating. As with magnetic enhancement in soils, the effect of heat on sediments is determined primarily by their initial magnetic makeup (Herries et al. 2007a). A number of factors can affect the thermo-magnetic enhancement of burnt deposits, including the type of combustion process used, contaminant mineralogy and fuel chemistry (Peters et al. 2002). Different fuel sources can often be determined from the magnetic mineralogy of ash residues (Peters et al. 2002). Mineralogically complex fuel-ash is normally confined to fuels such as coals and peat. Pure wood-ash, which would be expected to dominate Stone Age and Palaeolithic hearths, should cause no thermo-magnetic enhancement because wood itself is non-magnetic, but magnetic enhancement does occur due to small amounts of burnt sediment within the ash.

\section{South African soils and burning}

Over the last 10 years a series of samples have been collected from modern and ancient campfires in South Africa (Figure 1), to come to an understanding of the effect of fire on South African soils and sediments at different sites. Most often, heating causes the formation of fine-grained ferrimagnetic particles, which produces magnetic enhancement and high MS (Peters et al. 2001). The viscous grain sizes formed by heating can normally be detected by frequency dependence of MS (FD-MS [XFD\%]) (Thompson and Oldfield 1986). However, South African cave sediments already contain large amounts of these viscous magnetic grains due to pedogenesis and natural burning in the open landscape (Table 1; Figure 2 colluvium). Further burning causes a high concentration of ultra-fine (superparamagnetic) grains that are smaller than can be detected by this method using the standard Bartington (Ltd.) MS equipment. An increase in MS still occurs as these grain sizes are still easily magnetisable. However, rather than seeing an increase in FD-MS with heating, as seen at many Eurasian sites (Morinaga et al. 1999; Peters et al. 2001; Herries et al. 2007a), no change, or even a decrease in FD-MS is seen (Table 1).

In South Africa, the variation in this parameter is seemingly partly geographically dependant. At more coastal sites, such as Pinnacle Point and Sibudu Cave, a decrease in FD-MS is seen in conjunction with increased MS (Table 1; Figure 2 fire). At most inland sites, such as Grand Canyon Rockshelter (Limpopo Province), Rose Cottage Cave (Free State) and Molony's Kloof (Northern Cape) only a slight decrease or no change in FD-MS can be noted, although an increase in MS is still seen (Table 1). While a comparison of MS and FD-MS can still be used to identify burnt sediments in South Africa, not all burnt sediments can unequivocally be identified with this method unless detailed comparative mineralogical studies are undertaken. 


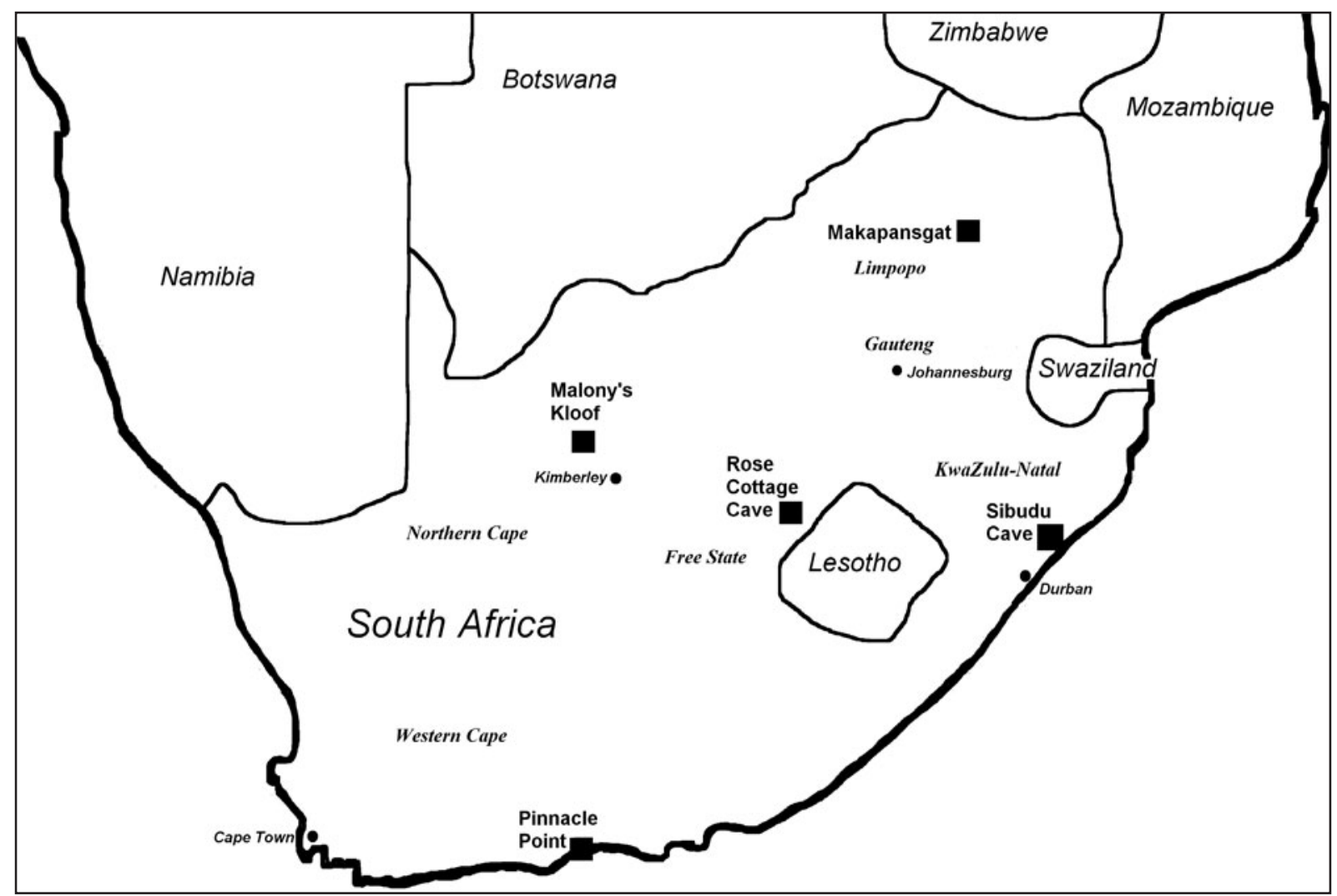

Figure 1. Location of archaeological sites studied in South Africa.

\begin{tabular}{lllll}
\hline Site & Location & State & MS & FD-MS \\
\hline Grand Canyon Rockshelter & Limpopo & unburnt & 278.4 & 11.4 \\
\hline Grand Canyon Rockshelter & Limpopo & mixed & 544.0 & 10.6 \\
Grand Canyon Rockshelter & Limpopo & burnt & 1876 & 9.37 \\
\hline Rose Cottage Cave & Free State & unburnt & 125.0 & 9.8 \\
\hline Rose Cottage Cave & Free State & mixed & 200 & 10.1 \\
\hline Rose Cottage Cave & Free State & burnt & 285.0 & 10.7 \\
\hline Molony's Kloof & Northern Cape & unburnt & 35.8 & 5 \\
\hline Molony's Kloof & Northern Cape & mixed & 160.0 & 6.6 \\
\hline Molony's Kloof & Northern Cape & burnt & 231.7 & 8.9 \\
\hline Pinnacle Point & Western Cape & unburnt & 1.1 & 0.0 \\
\hline Pinnacle Point & Western Cape & mixed & 41.0 & 8.8 \\
\hline Pinnacle Point & Western Cape & burnt & 138.0 & 2 \\
\hline KwaZulu Natal recent & KwaZulu Natal & unburnt & 750.0 & 12.5 \\
\hline KwaZulu Natal recent & KwaZulu Natal & natural burning & 900.0 & 12.0 \\
\hline Sibudu Cave & KwaZulu Natal & unburnt & 92 & 8.7 \\
\hline Sibudu Cave & KwaZulu Natal & mixed & 362 & 5.5 \\
\hline Sibudu Cave & KwaZulu Natal & burnt & 601 & 3 \\
\hline
\end{tabular}

Table 1. Magnetic susceptibility (MS) and frequency dependence of MS (FD-MS) for burnt, mixed and unburnt sediments from sites in different areas of South Africa. 
Low temperature magnetic susceptibility (LT-MS) provides another potential method for identifying burnt sediments as it can be used for identifying ultra-fine superparamagnetic (SP) grains that are formed by the heating process (Peters et al. 2002). SP grains do not hold a magnetic remanence, are slightly smaller than those detected by FD-MS and are the grain size formed by heating of sediments in South Africa. Larger stable single-domain (SSD) ferrimagnetic grains show little change in MS down to the temperature of liquid nitrogen $\left(-196^{\circ} \mathrm{C}\right)$. In contrast SP grains show a large drop in MS down to $-196^{\circ} \mathrm{C}$. The RS ratio is the ratio of $\mathrm{MS}$ at $+25^{\circ} \mathrm{C}$ to $\mathrm{MS}$ at $-196^{\circ} \mathrm{C}$. As such, SSD ferrimagnetic grains have an RS value close to 1 and SP values are much lower. The shape of the LT-MS can also be used to identify the mineralogy of the sample. SP magnetite will have a low RS ratio that is the same between -196 and $-150^{\circ} \mathrm{C}$ (the isotopic point of magnetite), causing the formation of a low temperature tail. Maghaemite does not have such a low temperature tail. Haematite can cause a variety of behaviours depending on its grain size and its MS behaviour at low temperatures is generally less well understood than for magnetite.

$$
\text { Burnt clays from }
$$
Bulgarian clay-built pottery kilns and LSA hearths from Rose Cottage Cave in South Africa show an LT-MS behaviour that is quite distinctive and suggests that a particular mineralogy

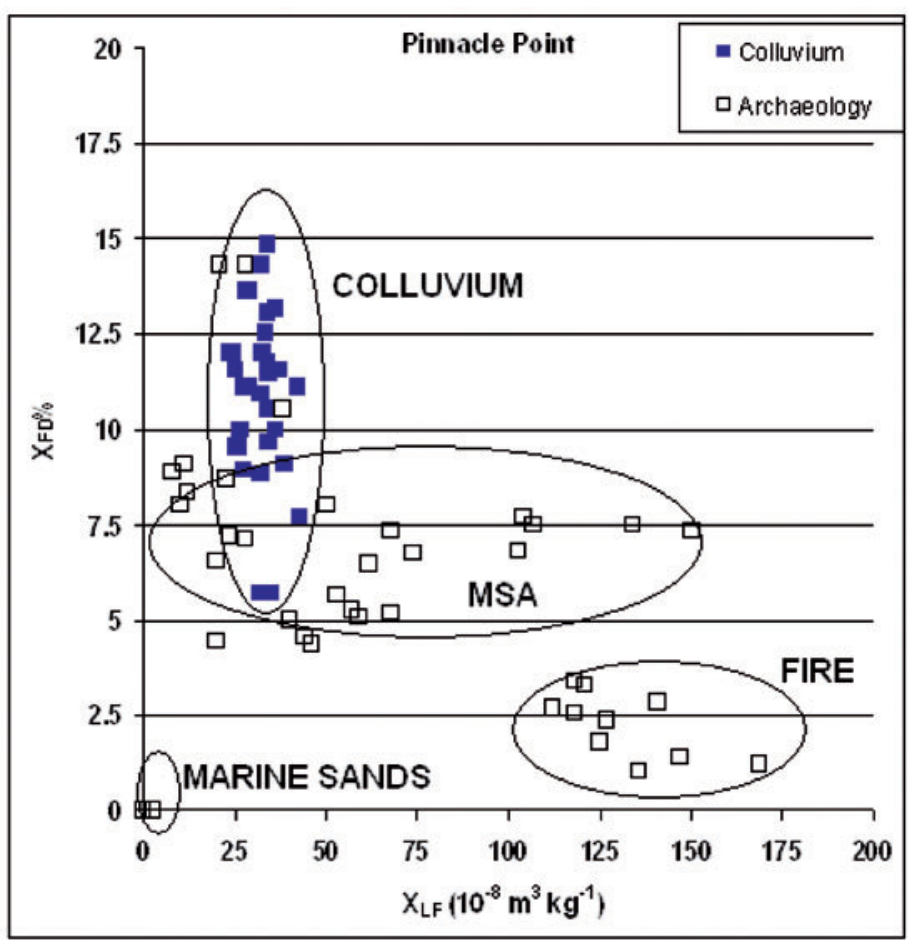

Figure 2. Frequency dependence of magnetic susceptibility (FD-MS; XFD\%) versus low frequency magnetic susceptibility (MS; XLF) data for modern soils, unaltered sand and archaeological layers and in situ hearths from MSA bearing Cave 13b at Pinnacle Point.

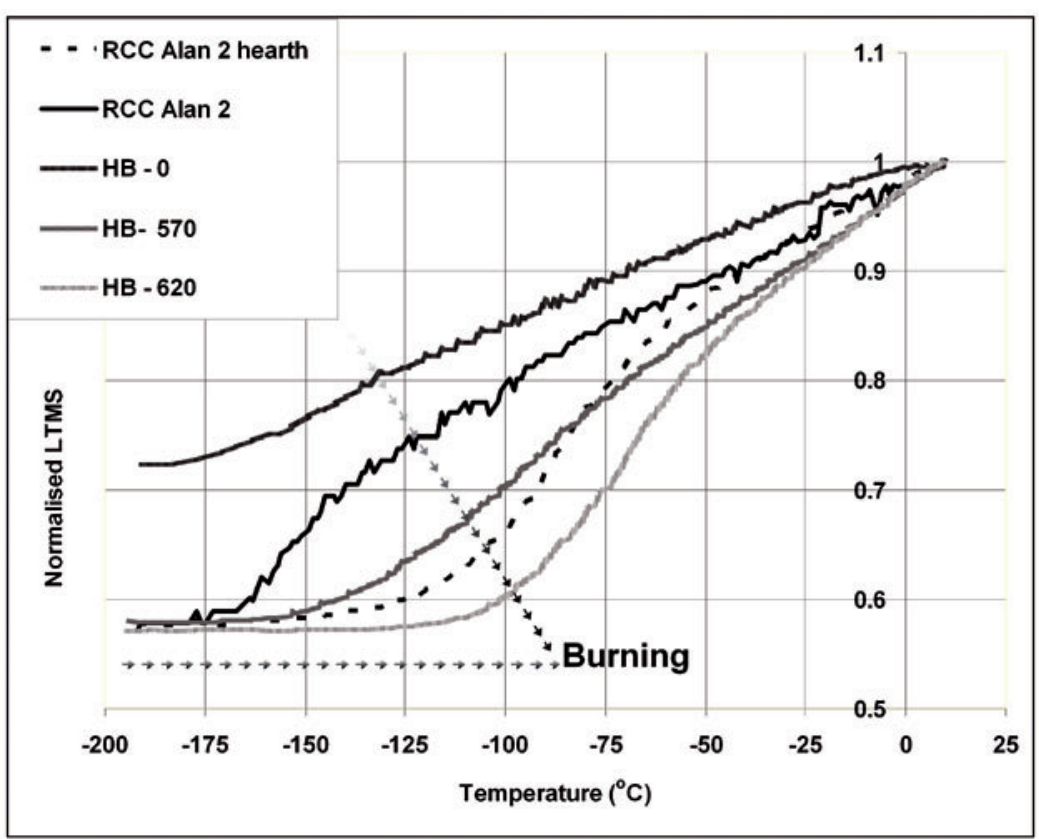

Figure 3. Low temperature magnetic susceptibility (LT-MS) data for unburnt and burnt LSA layer Alan 2 from Rose Cottage Cave and experimentally burnt clay samples from the Thracian site of Halka Bunar, Bulgaria. 
prevails, at least in more clay based sediments (Figure 3). Unburnt sediments have a typical SP character. Burnt sediments have a curve with a lower RS, a low temperature tail that prevails to temperatures above $-150^{\circ} \mathrm{C}$ and overall the cure has a more S-shaped nature. This is thought to be in part due to the formatio $\mathrm{n}$ of coarser grained haematite in the samples. Further work is need to clarify this but these data along with the work of Peters et al (2002) has shown the power of using LT-MS in identifying burnt deposits. Bellomo (1994) has also suggested certain magnetic parameters for identifying human/hominin burnt material. However, many of these will be dependent on the location of the site, lithology and climate among other things. As such, the use of archaeomagnetic methods to determine burning must always be on a case by case basis and use as many parameters and methods as possible. Magnetic enhancement will only be relative to the base mineralogy of the layer as it was before it was altered.

In the past, the colouration of sediments was taken as an indicator of burnt archaeological deposits. However, recent work has shown that reddening of sediments by burning only happens occasionally in campfires (Canti and Lindford 2000). Reddening of deposits is caused by the formation of haematite. While haematite can form at low temperatures in a heavily oxidising environment due to the transformation of maghaemite (Herries and Kovacheva 2007), it is fine grained and so does not affect many remanence properties. Courser grained haematite is often not produced until temperatures in excess of $600^{\circ} \mathrm{C}$ (Herries et al. 2007a). In most instances the temperature beneath most fires remains below $500^{\circ} \mathrm{C}$ and reddening of the soil happens only rarely (Canti and Lindford 2000). Moreover, more reducing conditions occur in sediments beneath the campfire and a reddening of deposits would be unlikely to occur as haematite would not be formed by oxidisation processes.

The identification of early fire use by hominins in the open landscape is difficult due to the occurrence of natural fires, particularly in Africa. Often coloured sediments in caves, where fires do not occur naturally, are considered to be more reliable indicators of the hominin/human use of fire. However, the work of Weiner et al. (1998) has also shown that coloured sediments at the Palaeolithic cave site of Zhoukoudian are due to entirely natural processes. At the Cave of Hearths, at Makapansgat, a series of coloured sediments and circular bone accumulations occurs in Early Stone Age (ESA) layers that have also been interpreted as early fire use (Mason 1988; Maguire 1998). Unaltered alluvial and colluvial sediments from Makapansgat (ZKL-003; GKC; Figure 4), and from the Cave of Hearths (PM, WWS; Figure 4) have high proportions of fine to ultra-fine VSD grains. Burnt sediments from the nearby Grand Canyon Rockshelter fall into two groups. The lower MS group represents unaltered colluviallyderived sediments. The higher MS group represent burnt sediments from a hearth at the site and show an increase in MS but a similar to lower FD-MS. The increase in MS is due to an increase in ultra-fine, SP magnetite during the process of burning. In contrast, the purported burnt ESA layers from the Cave of Hearths have low MS and FD-MS due to a lack of fine to ultra-fine VSD and SP grains (HWS; Figure 4). The layers therefore show no form of magnetic enhancement as would be expected from fire use or a mineralogy consistent with any documented burnt sediments. The magnetic mineralogy indicates that the fine-grained magnetite fraction, present in surrounding deposits (WWS, PM), is absent and has most likely been altered or destroyed by some other process. It is suggested that the coloured horizons actually represent waterlogged pool deposits, where complex mineralogical changes have occurred due to the presence of owl and bat guano. White ashy-looking horizons within the sequence consist of un-burnt and crushed rodent bones. This research has shown that there is no evidence of fire in the ESA horizons at the site.

In theory, the identification of heavily anthropogenically altered layers in a cave sequence is possible using these magnetic methods and may be used to identify heavily occupied layers or zones of an archaeological cave. If the base material is particularly unmagnetic, in the case of more sand- or claybased sediments, the identification of anthropogenic alteration, and therefore heavy occupation should be simpler. Figure 5 shows a section through the test trench of Sopeña Cave in Asturias, northern Spain. The sequence is dated to between the end of the Last Glacial Maximum 18-20,000 years and >38,000 years, and records the Mousterian to Upper Palaeolithic transition. The unaltered base sediment is clay-, sand- and silt-rich and has a low mean value of MS (X mean $\left.0.24 \times 10^{-6} \mathrm{~m}^{3} \mathrm{~kg}^{-1}\right)$. Little change in the MS is 
seen for the section that would suggest a climatically determined signal from variation in sedimentary input. However, there are four distinct layers that have enhanced MS values. Unaltered layers are dominated by more coarsegrained magnetite and some maghaemite. When these deposits are heated they convert to fine-grained magnetite and a large increase in magnetisation and MS is recorded. In contrast, burnt layers are dominated by ultra-fine-grained magnetite and do not alter on heating to $700^{\circ} \mathrm{C}$. The magnetic sequence at Sopeña Cave identifies four main levels of occupation at the site (Levels 3, 5, 7 and 13). However, a section through different parts of the cave may alter this picture as occupation may have taken place in different lateral areas of the cave at different periods.

Therefore, the task now is to try and recreate these data multi-dimensionally to create a three dimensional picture of anthropogenic alteration that could ultimately be used to identify spatial patterning of occupation within archaeological cave sites. Figure 6 shows a 3D GIS image of magnetic measurements undertaken at a Middle Stone Age (MSA) cave from Mossel Bay in South Africa (Marean et al.. 2007). Over 600 samples were measured from bulk samples taken during excavation of the site. The base sediment in the caves consists of magnetically weak dune sand and quartzitic roof spall. When the sediments are heated magnetite is formed. High MS values show close relationships

\section{Log MS $\left(10^{-6} \mathrm{~m}^{3} \mathrm{~kg}^{-1}\right)$}

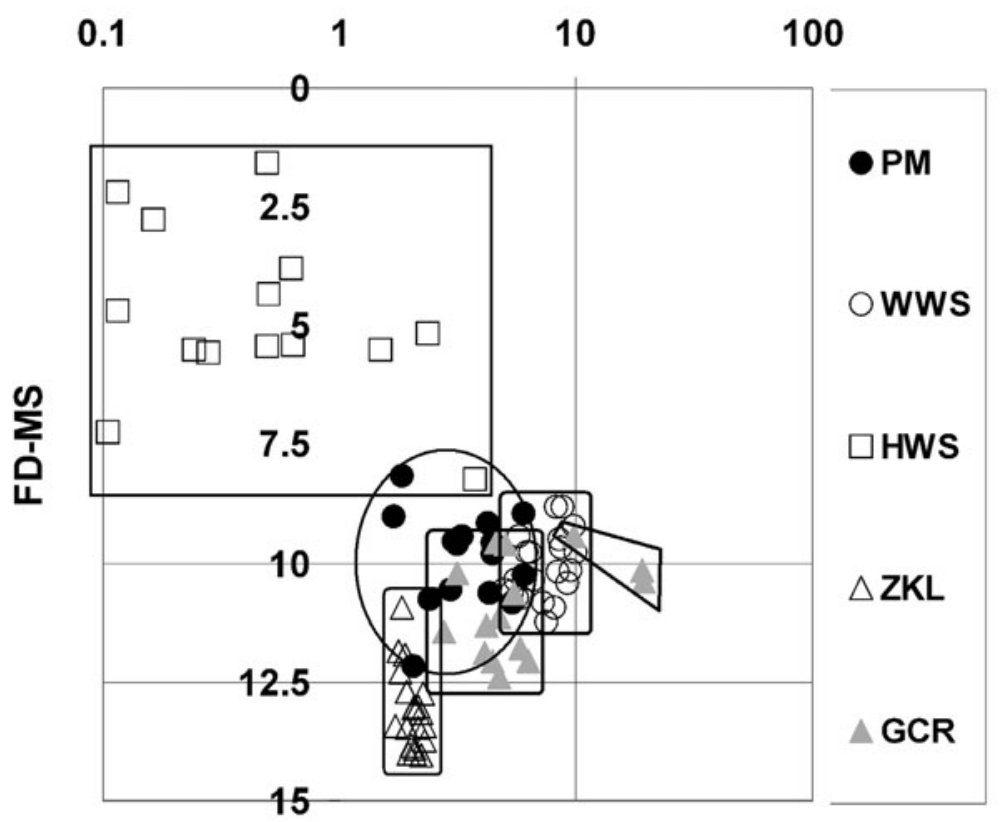

Figure 4. A comparison of FD-MS versus log MS for sites from Makapansgat, South Africa. Samples from site ZKL-003 represent alluvial sediments. Samples from Grand Canyon Rockshelter (GKC) represent colluvial sediments. The second grouping with higher MS and similar to low FD-MS represent hearth sediments from the site. WWS samples come from lightly calcified unaltered ESA layers of the Cave of Hearths. PM samples come from calcified ESA deposits of the Cave of Hearths and have lower MS values than the WWS due to the diluting influence of higher calcite content. HWS samples represent coloured horizons suggested to be evidence for hominin fire use from the ESA layers at the Cave of Hearths.

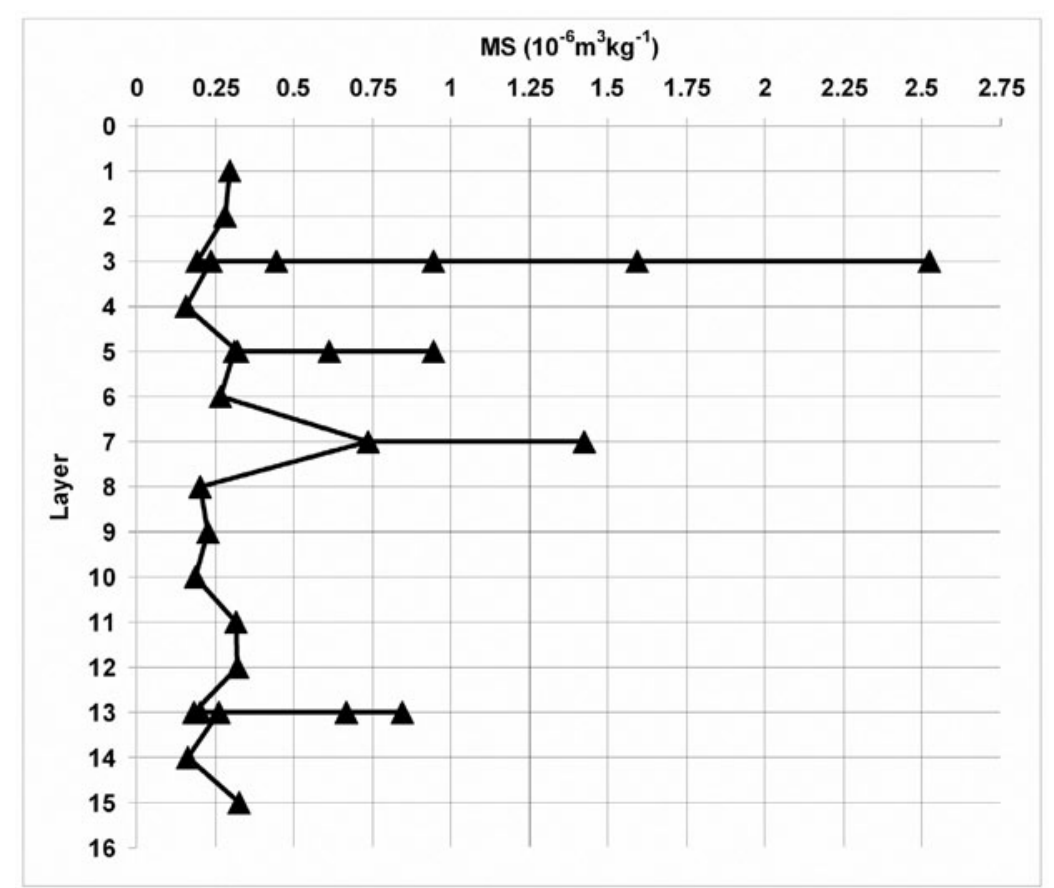

Figure 5. Increase in MS for heavily occupied layers from Sopeña Cave (Asturias, Spain) caused by anthropogenic alteration due to the use of fire. 
to 'burnt' stratigraphic units identified during excavation. Between these burnt units, lower MS values are recorded that represent the mixing of magnetically strong phases into magnetically weak sediments. This will be in part due to the movement of humans around the floor of the cave and can be used to delineate movement and occupation zones within the cave.

\section{Palaeoclimatic reconstruction}

Once an understanding of the effect of anthropogenic alteration on cave deposits has been established it is possible in some cases to recover palaeoclimatic information from Stone Age cave sites. In situ MS measurements were made for the entire excavated sequence at

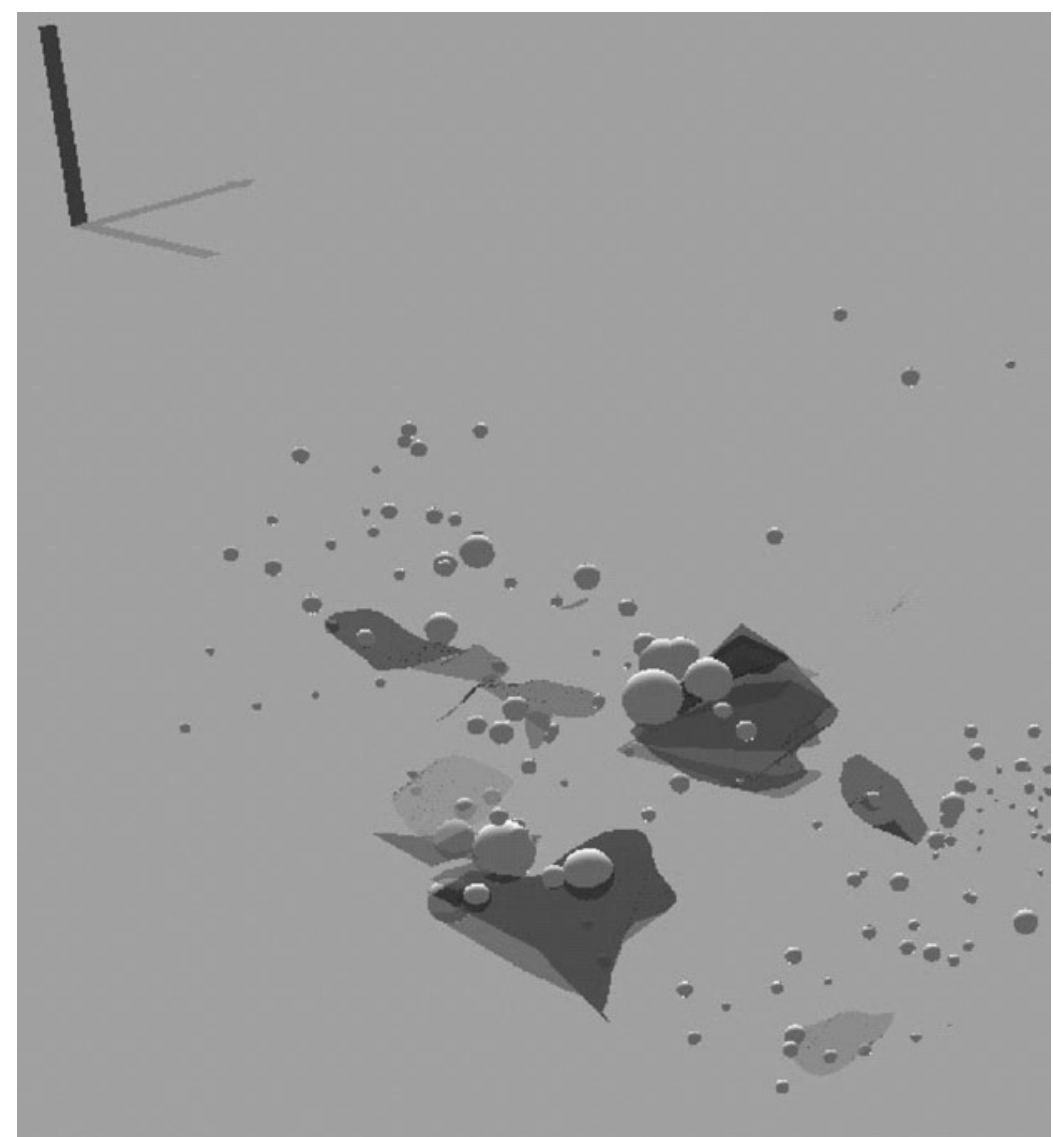

Figure 6. Three-dimensional GIS model of MS at the MSA bearing Pinnacle Point Cave 13B, Western Cape, South Africa. The spheres represent MS values (large sphere = high MS) plotted against stratigraphic units defined as burnt during excavation. (image by Erich Fisher, University of Florida).

Rose Cottage Cave in the Free

State of South Africa (Figure 7). The sequence covers the pre-Howiesonspoort (HP) MSA, HP, post-HP MSA, transitional MSA/Late Stone Age (LSA) and LSA period. Samples were additionally taken from each major layer within the sequence for laboratory analysis. A series of standard mineral magnetic tests (as per Walden et al. 1999) were undertaken on these laboratory samples to assess the reason for MS changes seen in the in situ sequence. Hearths are easily identified as they have very high MS values. Moreover, they are often well delineated in the upper sequence and so can be avoided during sampling.

Until recently, the older MSA sequence ( $>40 \mathrm{ka}$ ) had no reliable age estimates, but is important as it contains a HP occupation. The base of the sequence has been dated to $70 \mathrm{ka}$ using thermoluminescence (Valladas et al. 2005). Magnetic susceptibility variations of these deposits also suggest that the base of the MSA deposits were deposited at the transition from OIS $5 \mathrm{a}$ to OIS $4(\sim 68 \mathrm{ka})$. During the OIS 4 period $(\sim 58-68 \mathrm{ka})$ lower magnetic susceptibility values are recorded due to a decrease in the input of finegrained ferrimagnetic minerals and increased influence from diamagnetic and paramagnetic weathered sandstone fractions. The layers represented by the beginning of OIS $4(\sim 68 \mathrm{ka})$ contain the HP industry and are associated with spikes in MS related to in situ hearths. In situ hearths are easily identifiable in all layers of the sampled sequence in which they occur, as the MS values are between two and three times the value of the background values (Figure 7). A slow increase in MS represents the change from OIS 4 to OIS 3 with peak MS occurring around $50 \mathrm{ka}$. After this a fluctuating climate occurs before the MS values reach their lowest values around 14 to 20 ka during the Last Glacial Maximum. MS values then increase again to a maximum during the Holocene, around 7-5 ka. The MS sequence at Rose Cottage Cave shows up not only major changes in climate, such as the transition from more glacial to interglacial stages, but also small-scale fluctuations within the Holocene including an event at around 9.2-9.6 ka. 
At Sibudu Cave, in KwaZulu-Natal, a palaeoclimatic sequence has also been recovered. However, the processes and mechanisms behind the palaeoclimatic system are different (Herries 2006). The upper sequence covers the period between $>60 \mathrm{ka}$ and $40 \mathrm{ka}$ (Wadley and Jacobs 2006). Towards the base of this sequence a distinct mineral magnetic transition is noted with a change from sediments dominated by derived windblown soils containing high proportions of ultra-fine-grained magnetite and maghaemite in the top section to sediments in the base with little derived soil and an increased amount of haematite from weathering of

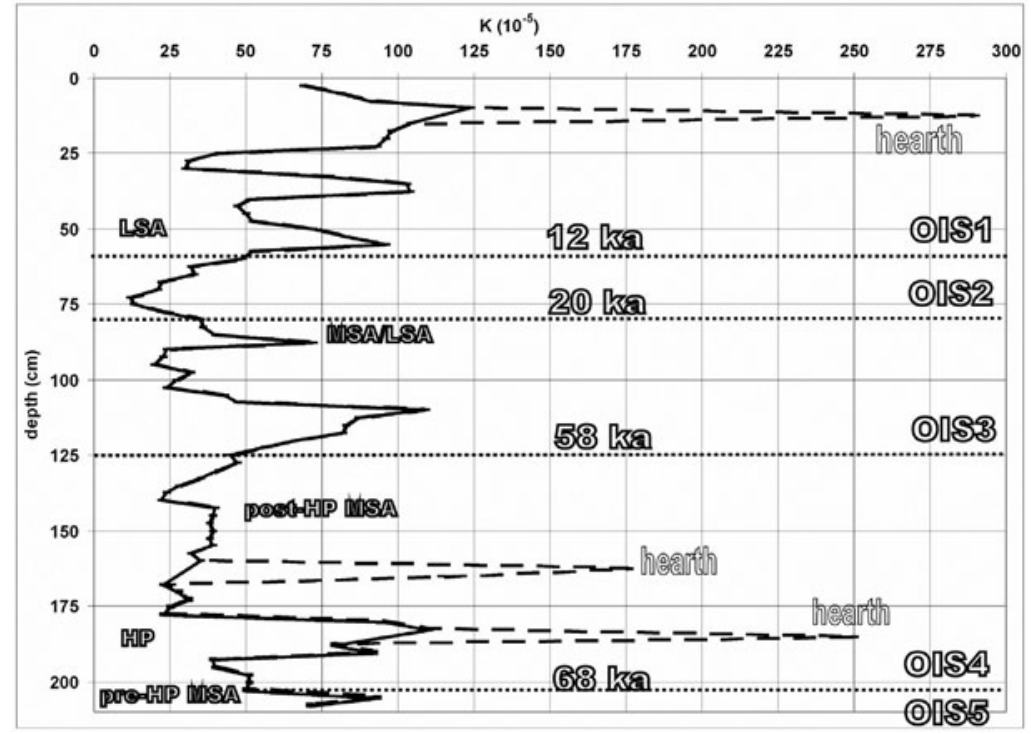

Figure 7. In situ magnetic susceptibility (K x10-5) curve versus depth $(\mathrm{cm})$, age and stone tool industries from an excavated section at Rose Cottage Cave over the last $70 \mathrm{ka}$. Spikes in MS that are related to in situ hearths are also shown. The cave has a pre-Howiesoon-spoort MSA (pre-HP MSA), Howiesoonspoort (HP), post-Howiesoonspoort MSA (post-HP MSA), MSA to LSA transitional industry (MSA/LSA) and a number of LSA industries.

\section{the sandstone rockshelter. This}

transition occurs at around $60 \mathrm{ka}$ (Herries 2006) and is linked to changes in pedogenesis, wind patterns and deposition of derived soils within the cave between the colder, more arid, low MS, OIS 4 and the warmer, high MS OIS 3. Ongoing analysis on the base of the MSA sequence again suggests that a Howiesonspoort industry occurs within OIS 4 (Wadley and Jacobs 2006). Because this site was heavily occupied by humans the sediments have undergone extensive anthropogenic alteration in certain areas due to fire use. As such, small changes and spikes in MS are not interpreted as climatically determined (Herries 2006). However, major climatic events such as the OIS 4 to 3 transition are still noted in multiple sections and show that the climatic signal is not entirely overprinted (Herries 2006).

\section{Sourcing and behaviour}

Ochre is found in MSA sites in South Africa (Marean et al.. 2007). As this material is highly magnetic it is also important to assess its contribution to the magnetic signal when conducting detailed archaeomagnetic studies of an archaeological cave and its deposits. Hysteresis loops, isothermal remanent magnetisation (IRM) acquisition curves and thermomagnetic curves were conducted on archaeological ochre from a MSA cave site near Mossel Bay using a variable field translation balance (VFTB). The samples also underwent X-ray diffraction experiments at Arizona State University. In most cases the mineral magnetic character is much more distinct than X-ray diffraction spectra and allowed a number of distinct magnetic ochre types to be distinguished. Figure 8 shows thermomagnetic curves for three ochre samples from the site. One sample has a Curie point (Tc) of $680^{\circ} \mathrm{C}$ and indicates the domina nce of haematite. Another sample has a Tc of $575^{\circ} \mathrm{C}$ that indicates the dominance of magnetite. The final s ample has a Tc of $620^{\circ} \mathrm{C}$ and a drop in magnetisation on heating that suggests the dominance of maghae mite. IRM acquisition curves and hysteresis loops indicate that while most red ochre samples contain haematite, some also contain magnetite and/or maghaemite. Further analysis utilising hysteresis loops and IRM acquisition curves can provide distinct mineralogies that can further characterise the ochre deposits. Mooney et al. (2003) conducted successful sourcing of ochre from Australia using combined 
X-ray diffraction and mineral magnetic methods to help characterise ochre. This work shows the great potential for sourcing ochre from Stone Age sites and therefore recovering valuable behavioural data on group ranges or even trading networks.

\section{Palaeomagnetism}

\section{Geomagnetic field variation}

Geomagnetic data consists of palaeo-directional measurements in the vertical (inclination) and horizontal (declination) plain as well as the intensity of the Earth's field. Unlike mineral magnetic studies, palaeomagnetic studies need to be undertaken on oriented samples if palaeo-directional or taphonomic data are to be recovered. However, for palaeointensity studies, samples need not be oriented. Perhaps the best known application of palaeomagnetic studies to archaeology is the dating of hominin bearing deposits using magnetostrati-

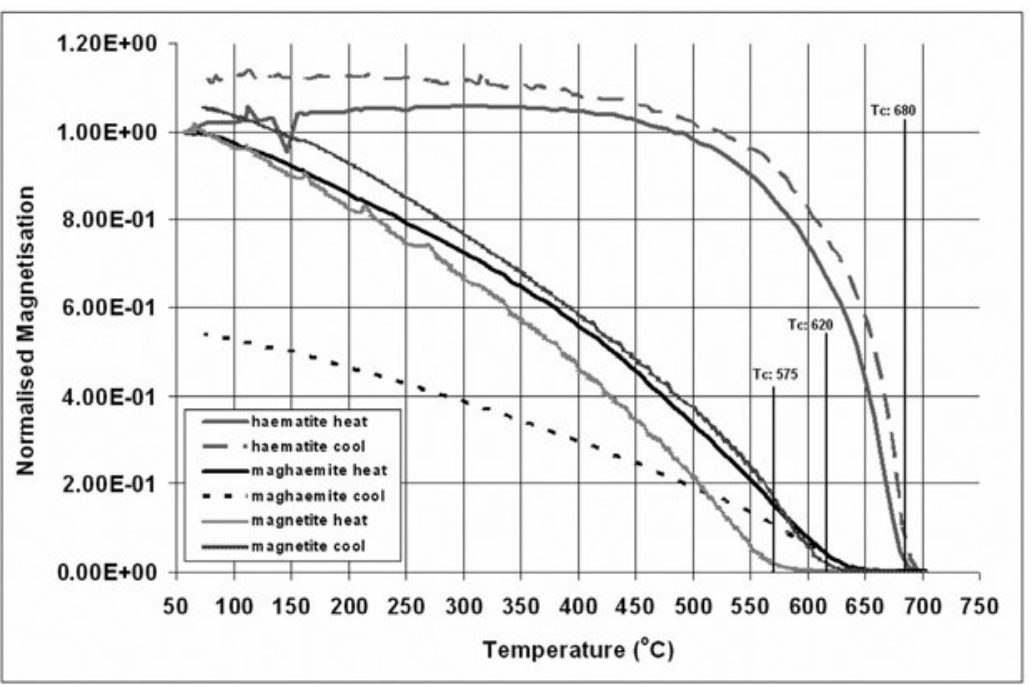

Figure 8. Thermomagnetic curves for three ochre samples from Pinnacle Point Cave 13B. One sample has a Curie point (Tc) of $680^{\circ} \mathrm{C}$ and indicates the dominance of haematite. One sample has a Tc of $575^{\circ} \mathrm{C}$ that indicates the dominance of magnetite. The final sample has a Tc of $620^{\circ} \mathrm{C}$ and a drop in magnetisation on heating that suggests the dominance of maghaemite.

graphic analysis (Tamrat et al.

1995; Lacruz et al. 2002; Zhu et al. 2003; Herries et al. 2006a, b). Reversal magnetostratigraphy works on the basis of comparing the fossil polarity of sediments on archaeological and fossil sites with the globally known variation in the Earth's magnetic field (Cande and Kent 1995; Ogg and Smith 2004).

Even when the dipole field has a steady polarity it undergoes swings in direction and variation in its intensity (Ogg and Smith 2004). This fluctuation, or 'secular variation', of the geomagnetic field over stable polarity time periods is also much less well defined, especially for earlier archaeological time periods and outside of Europe and the United States. Secular variation studies can be done using either the palaeo-direction and/or the palaeo-intensity of magnetisation of sediments, speleothems, lavas, or more normally in archaeological studies, burnt materials (Openshaw et al. 1993, Herrero-Bervera and Valet 2002; Herries et al. 2007a, b). When these were deposited or cooled they acquired a magnetic remanence (depositional remanent magnetisation or thermoremanent magnetisation) in the same direction as the Earth's ambient magnetic field. This remanence also has an intensity of magnetisation that is proportional to the strength of the magnetic field at that time. As the Earth's magnetic field gradually changes both direction and intensity, the direction and intensity of samples from the site can be compared and hence dated by comparison with the recorded direction and field intensity for past times at that locality, if they exist. In Europe, archaeomagnetic studies have been undertaken to develop regional archaeomagnetic curves that can be used to date archaeological sites and features (e.g. Kovacheva 1997; Herries et al. 2007a, b). As a dating method 'archaeomagnetic dating', as it is traditionally termed, has a typical accuracy of a few hundred years and an age range back to around $8 \mathrm{ka}$ (Kovacheva 1997), depending on the length and completeness of the archaeomagnetic record for the region under study. Unfortunately, for much of the world, especially the southern hemisphere and over most of the Stone Age time period, no comparative geomagnetic secular variation curve currently exists. The best records for this time period come from lake or marine sediments, where many post-depositional effects occur, or from lava sequences (Herrero-Bervera and Valet 2002; Roberts 2006). 
Archaeological sites provide a prime resource for the recovery of geomagnetic field data. In the southern hemisphere, particularly South Africa, the lack of a long term record of kiln and stone hearth construction has led to an inability to create an archaeomagnetic reference curve. The recent development of the microwave palaeointensity technique (Böhnel et al. 2003) enables much smaller samples, such as pottery, to be utilised to record geomagnetic field variation. As such, there is the potential in South Africa to create an archaeointensity record that covers at least the last 2000 years. To extend beyond this time period the only potential data are from Stone Age hearths. Heat-retainer hearths, as used in Australia, are ideal for this type of analysis and preliminary work in this area has been conducted by Barbetti (1977) and Barton and Barbetti (1983). However, few built hearths have been noted from southern Africa. Recent research has been undertaken on burnt rocks from South African Stone Age sites. These studies have a number of values: 1) the date recovered from in situ burnt rocks provides evidence for geomagnetic field changes over a much longer time range; 2 ) the method can identify burnt rocks that are in situ and their maximum temperature of heatinng; 3 ) this can be used along with magnetic mineralogical studies of burnt sediments to create a powerful tool for reconstructing site taphonomy.

\section{Palaeomagnetism and fire identification}

When sediments are deposited the grains orient themselves in the direction of the Earth's magnetic field and produce a depositional remanent magnetisation (DRM). This is retained after lithification with small changes occurring on dewatering and compaction, to form a post-depositional DRM (pDRM). Sand is not a good recorder of DRM due to the weakness of quartz and also its susceptibility to movement. However, sandstones can preserve a secondary chemical remanent magnetisation (CRM) due to the formation of haematite during lithification and weathering. This CRM will record the direction of the Earth's magnetic field at the time of its alteration. When blocks fall off the wall of a rockshelter they lose their orientation and their direction of remanence now lies in a random direction. When the rocks are incorporated into a fireplace, either deliberately or accidentally, and are heated they will acquire a thermoremanent magnetisation (TRM) in the direction of the ambient geomagnetic field (Figure 9).
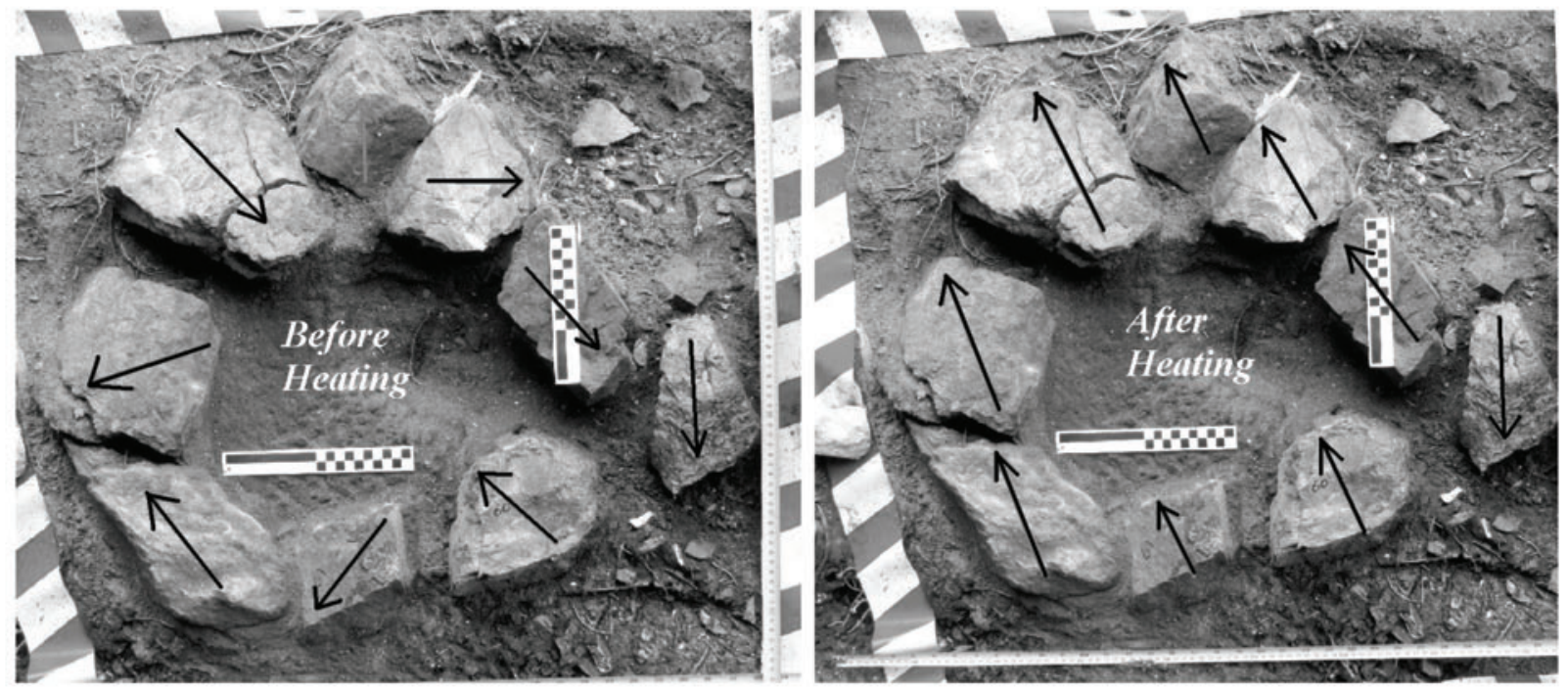

Figure 9. A rock-bound hearth from Western Cape. Before the rocks are heated their geological palaeodirection is in independent directions. When the rocks are heated a TRM is induced in the sample and their palaeodirection should be in the same direction. A sample outside the hearth will retain its original geological palaeodirection. 
If heated to above the Curie temperature (Tc) of the main remanence-carrying mineral, haematite $\left(680^{\circ} \mathrm{C}\right)$ or magnetite $\left(575^{\circ} \mathrm{C}\right)$, the CRM will be completely overprinted with a TRM and the rock will retain only a single field direction. An unheated rock will also record only a single field direction, however, it will have a weak CRM and its direction will be random. In contrast, a heated rock will retain a strong, single component in a normal (towards North) magnetic field direction. If the rock is not in situ it can still be distinguished from an unheated rock by its high intensity, as the strong ferrimagnetic mineral phase, magnetite $\left(\mathrm{Tc}=575^{\circ} \mathrm{C}\right)$, is normally formed during heating. No heating temperature information can be recovered other than that it was heated to above the Curie point. If heated to below the Tc, a partial thermomagnetic remanence (pTRM) is induced. Heating to temperatures below the ancient temperature of heating (ATc) will thermally demagnetise the pTRM. The temperature step at which the pTRM is removed and the magnetic vector changes to the randomised CRM of rock is the estimated last temperature of heating. Therefore, subsequent heating of the rock in the laboratory in small temperature increments $\left(25-50^{\circ} \mathrm{C}\right)$ and measurement between these temperature steps can help determine the maximum temperature of heating that the rock or stone artefact has experienced.

A series of experiments has been undertaken to determine the suitability of the palaeomagnetic vector method to different rock types and situations. Gose (2000) showed the potential of this method to stone-bound hearths during more recent periods in the United States. A series of bedrock sandstone samples from Carden Park Rockshelter was burnt in a campfire at the University of Liverpool to see if this material retained a measurable, stable TRM from heating in a hearth. The sandstone samples retained a normal geological magnetic polarity. The samples were placed into the fire in various positions and the campfire was stoked for one and a half hours. The maximum temperature of heating of various parts of the hearth was monitored with thermocouples to confirm the accuracy of the maximum temperature of heating method (Figure 10). Sample BSSB1A came from the surface of the sample and was placed at 90 degrees to the normal geological remanence of the sample and in the same vertical plain. The mean modern overprint that is recorded in the samples was 354 degrees declination by +65.8 degrees inclination. The modern field at the location was 355.5 degrees by +67.9. This suggests that sandstone fulfils the first requirement of recording the current Earth's field accurately. Thermocouples gave a maximum temperature for the fire above the burnt rock of $395^{\circ} \mathrm{C}$. The base of the rock gave a maximum temperature of $315^{\circ} \mathrm{C}$. The estimate for the maximum temperature of heating using the palaeomagnetic vectors method was between 300 and $400^{\circ} \mathrm{C}$ for all the samples (these are the temperatures between which the magnetic components switch direction; Figure 10). This suggests that this method is reliable for determining both the direction of the ancient magnetic field and the approximate temperature of last heating that has occurred. By undertaking thermal demagnetisation in smaller temperature stages and by paying careful attention to the location of the rocks and samples within the morphology of the fireplace, this estimate could be refined.

Studies of a modern hearth from Makapansgat, in the Limpopo Province of South Africa, have shown that burnt quartzite can successfully record palaeo-directional data, although the samples are often so weak that a very sensitive magnetometer is needed. The modern field direction at Makapansgat is 346.2 degrees declination and -54.7 degrees inclination (IGRF reference field accessed through the British Geological Survey). Burnt rocks from the modern fireplace at Makapansgat record a mean direction of 345.9 degrees declination and -55.1 degrees inclination (Table 2). A third rock (MAKMOD3; Table 2) from the fireplace was not included in the mean as it had obviously been moved since heating. A vector change occurs between 350 and $400^{\circ} \mathrm{C}$ and indicates that the rocks were heated to a maximum temperature of $350^{\circ} \mathrm{C}$ (Figure 11). The rocks therefore record both a pTRM from the modern heating and the original geological remanence. These data further support the ability of this method to record reliable palaeodirections and palaeotemperatures in different rocks in different parts of the world. 

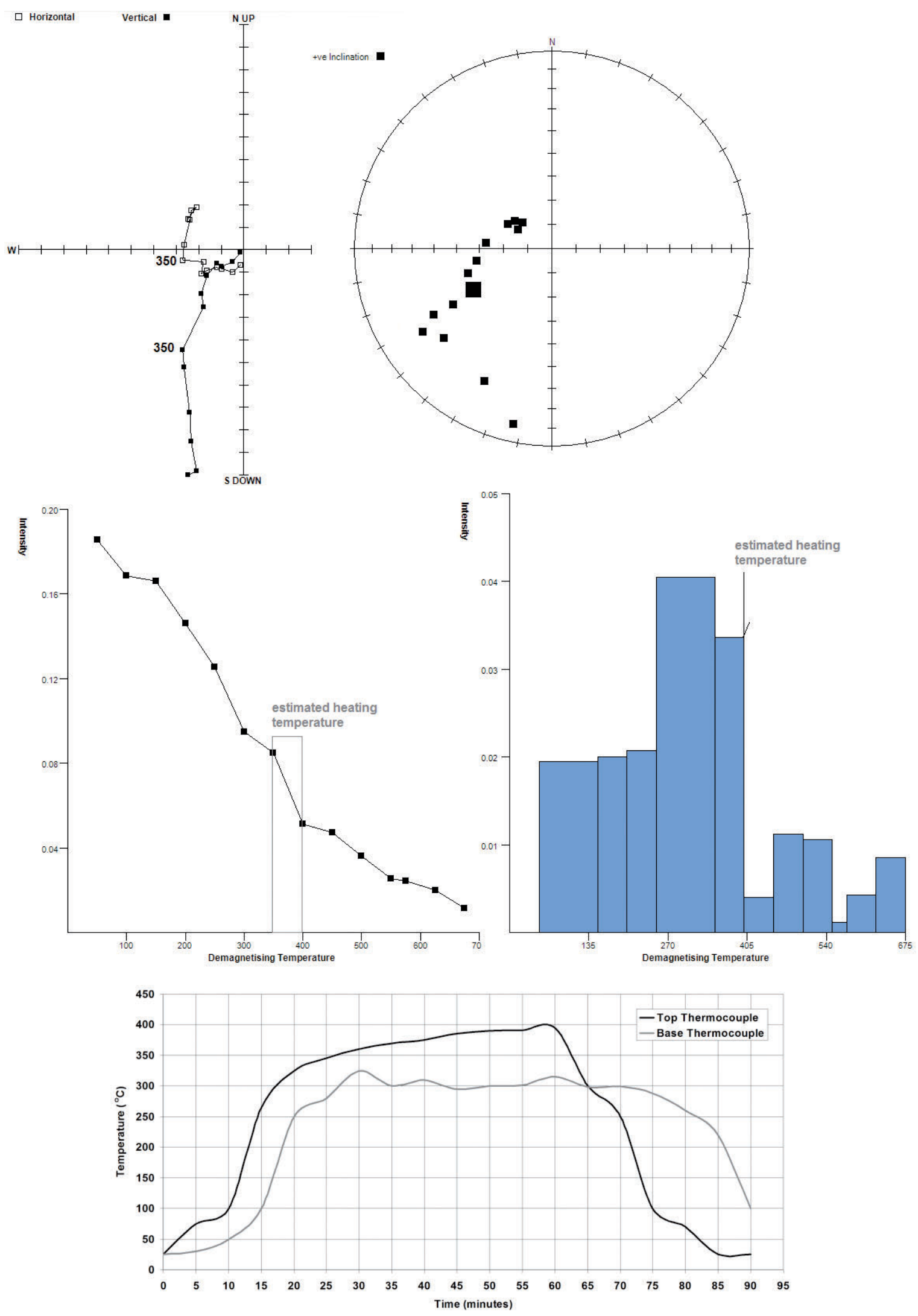

Figure 10. Magnetic data for a sample from an experimental hearth at the University of Liverpool, U.K: a) orthogonal plot; b) stereo plot; c) intensity plot; d) spectrum plot; and e) a plot of time versus temperature for thermocouples associated with the burnt rock (above and below). 

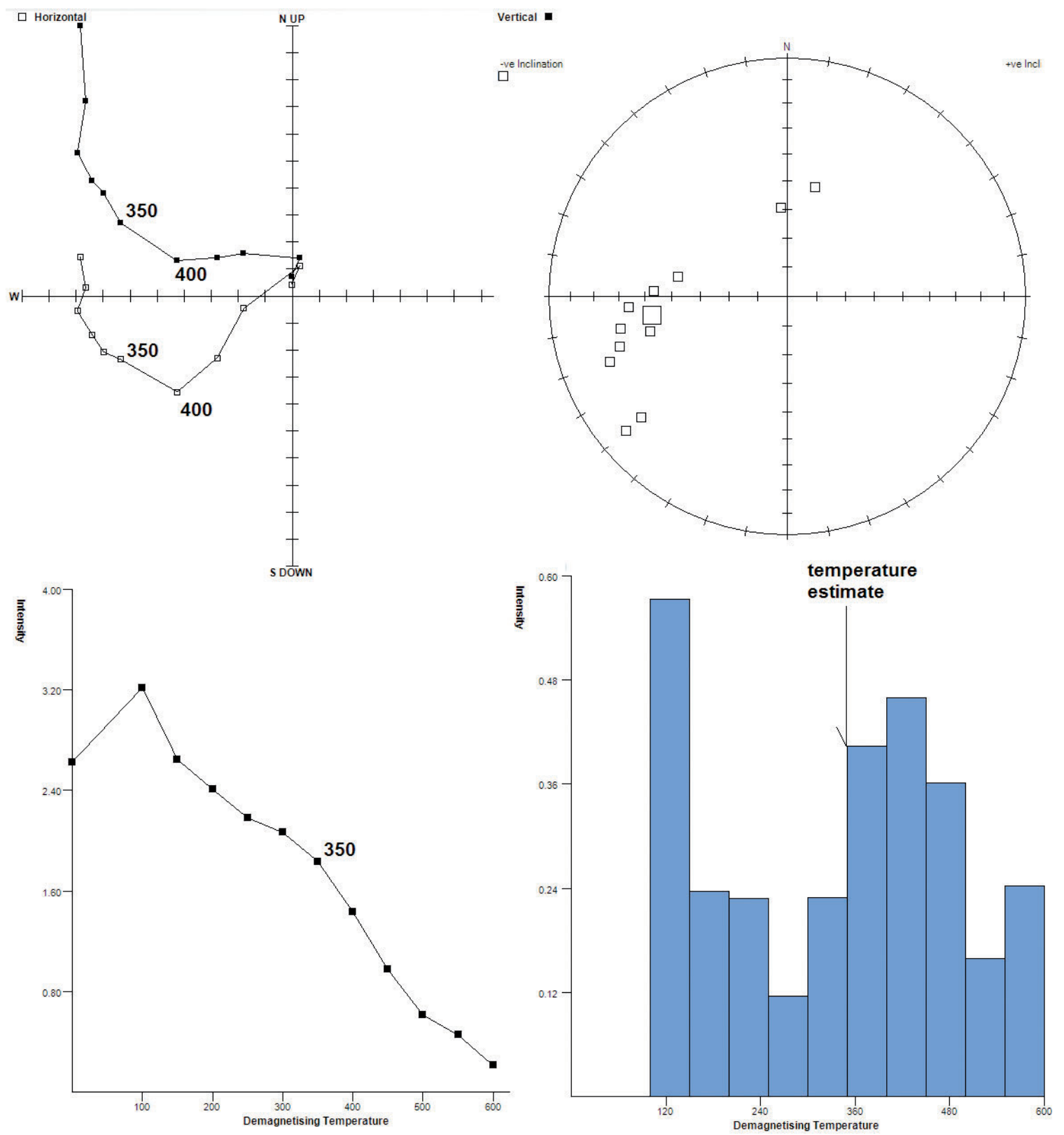

Figure 11. Magnetic data for a sample for a modern hearth at Makapansgat in Limpopo Province, South Africa.

However, recovering reliable data from Stone Age sites is dependent on a number of factors. How successfully the geomagnetic field is recorded will be partially dependent on the morphology of the fireplace. Rocks that surround fireplaces have the tendency to be moved after or between heatings and so many do not retain the correct modern field direction. This is shown by the unreliable directions from rock MAKMOD3 (Table 2). Those that lie within the fire appear to generally be more reliable (MAKMOD1; Table 2) but if too small may be moved during restocking of the fire. Those that are embedded in sediments underneath fireplaces, either as heat retainers or accidentally heated, will generally record the field more accurately as they are not subjected to movement, but they will be heated to a lower temperature than those directly in the hearth (MAKMOD2). Thus, the biggest obstacle to recovering secular variation data from Stone Age sites is normally the size of the burnt rocks along with the weakness of the host rock, the morphology of the hearth and the rocks location within it. However, while palaeodirectional data may not be recoverable, it is still possible to identify a number of things 
from the burnt rocks. If the samples have been heated to less than the Tc of the remanence-carrying mineral (normally magnetite, $575^{\circ} \mathrm{C}$ ), then both the pTRM induced in the sample from heating and the original geological remanence can be separately identified as with sample MAKMOD3 (Table 2). Also, not all rock types are amenable to this method, mainly due to the lack of magnetic material or the inability to measure such weak samples. Studies of flint from the Middle Pleistocene site of Beeches Pit in the U.K (Haritou 1996; Gowlett 2006), and limestone from the late Pleistocene site of Sopeña in Spain have shown that not all rocks are ideal for this method of analysis.

At Sibudu Cave, in the Kwazulu-Natal, a number of firing events have been discovered throughout the MSA layers of the site (Herries 2006; Wadley and Jacobs 2006). These occur as both discrete, shallow fire pits and as simple scatters of ash and coloured sediment. By looking at the fossil directions of magnetisation within a number of sandstone blocks recovered from these features and horizons, it was hoped to identify the primary heating contexts from secondary ash scatters. A number of rocks taken from 'ashy layers' in the trial trench showed no evidence of burning with a weak NRM and a weak single component of magnetisation. FTIR analysis of the ashy material identified it as gypsum. Naturally forming gypsum nodules were then noted in a number of layers at the site. These gypsum nodules formed during periods of hiatus at the site, as shown by rapid jumps in magnetic susceptibility and OSL dates (Herries 2006; Wadley and Jacobs 2006). However, thermal demagnetisation of sandstone from a number of fire pits at the site gave meaningful directions that estimated the maximum temperatures of heating to be around $450-500^{\circ} \mathrm{C}$ in some cases (Figure 12). Two separate samples from the same fireplace also gave relatively reliable palaeodirection results (Table 2: SIBBGY1 and SIBBGY2; Figure 12a, 12b) A burnt dolerite tool (SIBBDT1; Table 2) from the site was also sampled and while it did not give a reliable palaeodirection, it did give a consistent temperature of heating around $500^{\circ} \mathrm{C}$ (Figure 12c). As such, the method can also be used to look at the heat treatment of stone tools (Brown et al., 2008).

\begin{tabular}{|lllll|}
\hline Sample & Dec. & Inc. & MAD & Palaeotemp \\
\hline CARP1a & 353.6 & 65.3 & 5.7 & $350-400$ \\
\hline CARP1b & 352.4 & 69.3 & 6.9 & $350-400$ \\
\hline CARP2a & 356.5 & 63.4 & 8.3 & $300-350$ \\
\hline CARP2b & 349.9 & 65.4 & 7.2 & $300-350$ \\
\hline CARP3a & 357.4 & 66.3 & 5.4 & $350-400$ \\
\hline CARP3b & 354.2 & 65.2 & 4.4 & $350-400$ \\
\hline mean & 354.0 & 65.8 & & \\
Modern & 355.5 & 67.9 & & \\
\hline MAKMOD1a & & & & $350-400$ \\
\hline MAKMOD1b & 344.4 & -54.6 & 7.6 & $350-400$ \\
\hline MAKMOD2a & 346.4 & -58.2 & 5.6 & $300-350$ \\
\hline MAKMOD2b & 341.5 & -52.3 & 6.7 & $300-350$ \\
\hline MAKMOD3a & 351.3 & -55.4 & 4.2 & $300-350$ \\
\hline MAKMOD3b & 312.2 & -44.3 & 6.7 & \\
\hline mean & 302.9 & -40.5 & 8.2 & $450-500$ \\
Modern & 345.9 & -55.1 & & $400-450$ \\
\hline SIBBDT1 & 346.2 & -54.7 & & $400-450$ \\
\hline SIBBRSP1 & 351.7 & -3.9 & 3.4 & \\
\hline SIBBRSP2 & 30.1 & -43.8 & 5.6 & \\
\hline mean & 31.6 & -39.6 & 6.7 & \\
\hline
\end{tabular}

Table 2. Palaeodirectional data for burnt rock samples from an experimental fire at Carden Park (CARP), a modern fire at Makapansgat (MAKMOD) and MSA samples from Sibudu Cave (SIBB). 

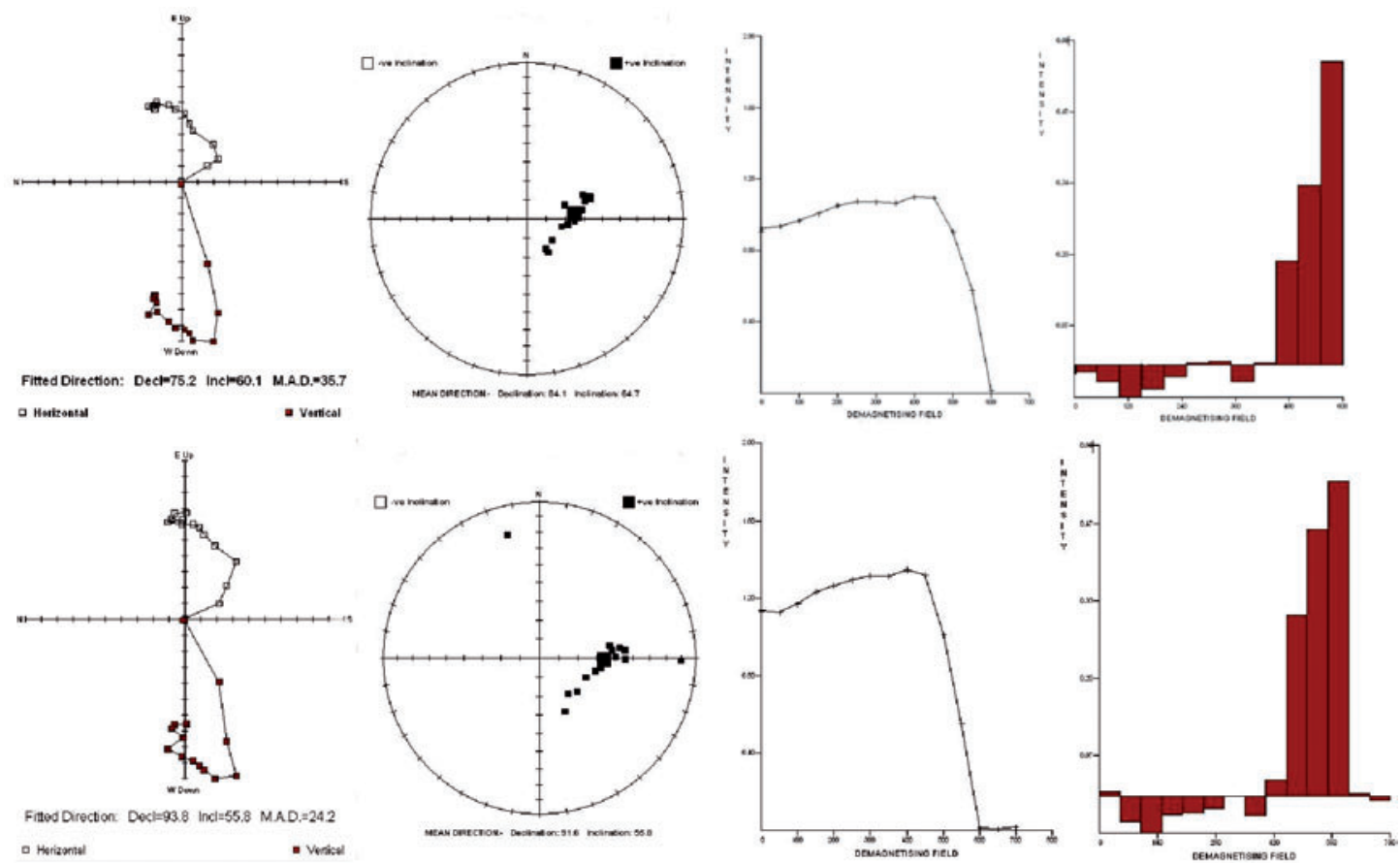

Figure 12. Magnetic data for two burnt rocks from a MSA hearth ( $50 \mathrm{ka})$ at Sibudu Cave, KwaZulu-Natal, South Africa.

\section{Conclusions}

This paper illustrates the potential of magnetic methods of analysis, subsumed under the term archaeomagnetism, for recovering information useful for archaeologists including:

- dating

- palaeoclimatic reconstruction

- behaviour:

1. evidence for fire use

2. spatial patterning of occupation

3. heating temperature and taphonomy of burnt rocks and stone tools

4. sourcing of artefacts.

\section{Acknowledgments}

All archaeomagnetic work was undertaken at the Liverpool University Geomagnetism Laboratory (U.K.) with the support of Alf Latham (Archaeology) and John Shaw (Earth Sciences). Work on the South African hominin sites and work at Sibudu and Rose Cottage caves and the Cave of Hearths was funded by the Arts and Humanities Research Board (U.K.) studentship number 99/3050. The work at Pinnacle Point was conducted as part of the Mossel Bay Archaeological (MAP) and SACP4 projects, run by Curtis Marean of the Institute of Human Origins, Arizona State University and funded by the National Science Foundation (USA) (grants \# BCS-9912465, BCS-0130713, and BCS-0524087 to Marean), the Hyde Family Trust, the Institute of Human Origins, and Arizona State University. Thanks to the South African Heritage Resources Agency (SAHRA) and Heritage Western Cape (HWC) for providing permits to conduct excavations at the selected sites and export specimens for analysis. Thanks to Kevin Kuykendall, Lyn Wadley, Curtis Marean, Anthony Sinclair and Darren Curnoe for support and access to archaeological sites. 


\section{References}

Barbetti, M. 1977. Measurements of recent geomagnetic secular variation in southeastern Australia and the question of dipole wobble. Earth and Planetary Science Letters 36:207-218.

Barton, C. E. and M. Barbetti. 1982. Geomagnetic secular variation from recent lake sediments, ancient fireplaces and historical measurements in southeastern Australia. Earth and Planetary Science Letters 59:375-387.

Bellomo, R. V. 1994. A methodological approach for identifying archaeological evidence of fire resulting from human activities. Journal of Archaeological Science 20:525-555.

Begét, J. E. 2001. Continuous Late Quaternary proxy climate records from loess in Beringia. Quaternary Science Reviews 20:499-507.

Böhnel, H., A. J. Biggin, D. Walton, J. Shaw and J. A. Share. 2003. Microwave palaeointensities from a recent Mexican lava flow, baked sediments and reheated pottery. Planetary Science Letters 214:221236. Brown, K., Marean, C. Robert, D., Herries, A., Braun, D. Tribolo, C. Jacobs, Z.. Atanasova, M. (2008) First documentation of heat treatment of silcrete in the Howieson's Poort and still Bay Middle Stone Age industries, Southern Cape, South Africa. Paleoanthropology 2008: A5.

Brown, K., Marean, C. Roberts, D., Herries, A., Braun, D. Tribolo, C. Jacobs, Z.. Atanasova, M. (2008) First documentation of heat treatment of silcrete in the Howieson's Poort and Still Bay Middle Stone Age industries, Southern Cape, South Africa. Paleoanthropology 2008: A5.

Cande, S. C. and D. V. Kent. 1995. Revised calibration of the geomagnetic polarity timescale for the Late Cretaceous and Cenozoic. Journal of Geophysical Research 100:6093-6095.

Canti, M. G. and N. Linford. 2000. The effects of fire on archaeological soils and sediments: Temperature and colour relationships. Proceedings of the Prehistoric Society 66:385-395.

Dalan, R. A. and S. K. Banerjee. 1998. Solving archaeological problems using techniques of soil magnetism. Geoarchaeology 13:3-36.

Ellwood, B. B., K. M. Petruso and F. B. Harrold. 1997. High-resolution paleoclimatic trends for the Holocene identified using magnetic susceptibility data from archaeological excavations in caves. Journal of Archaeological Science 24:569-573.

Gose, W. A. 2000. Palaeomagnetic studies of burned rocks. Journal of Archaeological Science 27:409-421.

Gowlett, J. A. J. 2006. The early settlement of northern Europe: Fire history in the context of climate change and the social brain. Comptes Rendus Palevol 5:299-310.

Haritou, S. J. A. 1996. Palaeomagnetism as an indication of hominid fire use: Analysis of flint and clay from Beeches Pit excavation 1996, West Stow, Suffolk, England. Unpublished M.Sc. thesis, University of Liverpool, U.K.

Herrero-Bervera, E. and J.-P. Valet. 2002. Paleomagnetic secular variation of the Honolulu Volcanic Series (33-700 ka), O'ahu (Hawaii). Physics of the Earth and Planetary Interiors 133:83-97.

Herries, A. I. R. 2006. Archaeomagnetic evidence for climate change at Sibudu Cave. Southern African Humanities 18:131-147.

Herries, A. I. R., J. W. Adams, K. L. Kuykendall and J. Shaw. 2006. Speleology and magnetobiostratigraphic chronology of the GD 2 locality of the Gondolin hominin-bearing paleocave deposits, North West Province, South Africa. Journal of Human Evolution 51:617-631.

Herries, A. I. R and M. Kovacheva. 2007. Using archaeomagnetism to answer archaeological questions at the Thracian site of Halka Bunar, Bulgaria. Archaeologia Bulgarica 11, in 2007/3, 25-46.

Herries, A. I. R., M. Kovacheva, M. Kostadinova and J. Shaw. 2007. Archaeo-directional and -intensity data from burnt structures at the Thracian site of Halka Bunar (Bulgaria): The effect of magnetic mineralogy, temperature and atmosphere of heating in antiquity. Physics of the Earth and Planetary Interiors 162, 199-216.

Herries, A. I. R. and A. G. Latham. 2003. 'Environmental archaeomagnetism': Evidence for climatic change during the later Stone Age using the magnetic susceptibility of cave sediments from Rose Cottage Cave, South Africa. In P. Mitchell, A. Haour and J. Hobart (eds), Researching Africa's past: New contributions from British archaeologists, pp 25-35. School of Archaeology Monograph 57. Oxford: Oxford University. 
Herries, A. I. R, K. Reed, A. G. Latham and K. L. Kuykendall. 2006. Speleology and magnetobiostratigraphic chronology of the Buffalo Cave fossil bearing palaeodeposits, Makapansgat, South Africa. Quaternary Research 66:233-245.

Kovacheva, M. 1997. Archaeomagnetic database from Bulgaria: The last 8000 years. Physics of the Earth and Planetary Interiors 102:145-151.

Lacruz, R.S, J. S. Brink, J. Hancox, A. S. Skinner, A. Herries, P. Schmidt and L. R. Berger. 2002. Palaeontology, geological context and palaeoenvironmental implications of a Middle Pleistocene faunal assemblage from the Gladysvale Cave, South Africa. Palaeontologia Africana 38:99-114.

Liu, X. M, P. Hesse, T. Rolph and J. E. Begét. 1999. Properties of magnetic mineralogy of Alaskan loess: Evidence for pedogenesis. Quaternary International 93:93-102.

Maguire, J. M. 1998. Makapansgat: A guide to the palaeontological and archaeological sites of the Makapansgat valley. Excursion guide for the Dual Congress of the International Association for the Study of Human Palaeontology and International Association of Human Biologists. Sun City, Republic of South Africa.

Maher, B. A. 1998. Magnetic properties of modern soils and Quaternary loessic paleosols: Paleoclimatic implications. Palaeogeography, Palaeoclimatology, Palaeoecology 137:25-54.

Maher, B. A. and R. Thompson. 1995. Paleorainfall reconstructions from pedogenic magnetic susceptibility variations in the Chinese loess and paleosols. Quaternary Research 44:383-391.

Mason, R. J. 1988. Cave of Hearths Makapansgat, Transvaal. Archaeology Research Unit Occasional Paper 21. Johannesburg: University of the Witwatersrand Press.

Marean, C.W., Bar-Matthews, M, Bernatchez, J., Fisher, E., Glodberg, P., Herries, A.I.R., Jacobs, Z., Jerardino, A., Karkanas, P., Minichillo, T., Nilssen, P.J., Thompson, E., Watts, I., Williams, H.W., 2007. Early Human use of marine resources and pigment in South Africa during the Middle Pleistocene. Nature. 449, 905-908.

Mooney, S. D., C. Geiss and M. A. Smith. 2003. The use of mineral magnetic parameters to characterize archaeological ochres. Journal of Archaeological Science 30:511-523.

Morinaga, H., H. Inokuchi, H. Yamashita, A. Ono and T. Inada. 1999. Magnetic detection of heated soils at Palaeolithic sites in Japan. Geoarchaeology 14:377-399.

Mullins, C.E. 1977. Magnetic susceptibility of the soil and its significance in soil science - a review. Journal of Soil Science 28:223-246.

Ogg, J. G. and A. G. Smith. 2004. The geomagnetic polarity time scale. In F. Gradstein, J. Ogg and A. Smith (eds), A geologic time scale 2004, pp 63-86. Cambridge: Cambridge University Press.

Openshaw, S. J., A. Latham, J. Shaw and Z. Xuewen. 1993. Preliminary results on recent palaeomagnetic secular variation recorded in speleothems from Xingwen, Sichuan, China. Cave Science 20:93-99.

Peck, J. A., R. R. Green, T. Shanahan, J. W, King, J. T. Overpeck and C. A. Scholz. 2004. A magnetic mineral record of Late Quaternary tropical climate variability from Lake Bosumtwi, Ghana. Palaeogeography, Palaeoclimatology, Palaeoecology 215:37-57.

Peters, C., M. J. Church and C. Mitchell. 2001. Investigation of fire ash residues using mineral magnetism. Archaeological Prospection 8:227-237.

Peters, C., R. Thompson, A. Harrison and M. J. Church. 2002. Low temperature magnetic characterisation of fire ash residues. Physics and Chemistry of the Earth 27:1355-1361.

Roberts, A.P. 2006. High-resolution magnetic analysis of sediment cores: Strengths, limitations and strategies for maximizing the value of long-core magnetic data. Physics of the Earth and Planetary Interiors 156:162-178.

Tamrat, E., N. Thouveny, M. Taieb and N. D. Opdyke. 1995. Revised magnetostratigraphy of the Plio-Pleistocene sedimentary sequence of the Olduvai Formation (Tanzania). Palaeogeography, Palaeoclimate, Paleoecology 114:273-283.

Thompson, R. and F. Oldfield. 1986. Environmental magnetism. London: Allen and Unwin.

Valladas, H., L. Wadley, N. Mercier, L. Froget, C. Tribolo, J. L. Reyss and J. L. Joron. 2005.

Thermoluminescence dating on burnt lithics from Middle Stone Age layers at Rose Cottage Cave. South African Journal of Science 101:169-174. 
Wadley, L. and Z. Jacobs. 2006. Sibudu Cave: Background to the excavations, stratigraphy and dating. Southern African Humanities 18:1-26.

Weiner, S., Q. Xu, P. Goldberg, J. Liu and O. Bar-Yosef. 1998. Evidence for the use of fire at Zhoukoudian, China. Science 281:251-253.

Williamson, D., A. Jelinowska, C. Kissel, P. Tucholka, E. Gibert, F. Gasse, M. Massault, M. Taieb, E. Van Campo and K. Wieckowski. 1998. Mineral-magnetic proxies of erosion/oxidation cycles in tropical maar-lake sediments (Lake Tritrivakely, Madagascar): Paleoenvironmental implications. Earth and Planetary Science Letters 155:205-219.

Zhu, R., Z. An, R. Potts and K. A. Hoffman. 2003. Magnetostratigraphic dating of early humans in China. Earth-Science Reviews 61:341-359. 